\title{
Research on the basis of foam glass substrates with additions of copper compounds
}

\author{
Yuriy Dmitriyev ${ }^{1 *}$, Eugene Yurchenko ${ }^{1}$, Elena Yurchenko $^{1}$, Astkhyk Kakosyan ${ }^{1}$, and Elena \\ Vorobei $^{1}$ \\ ${ }^{1}$ Sochi State University, 354000, 94, Plustunskaya St., Sochi, Russia
}

\begin{abstract}
Obtained artificial substrates, representing a porous glass (foam glass) with additives of 3 to $10 \%$ of the mass. copper ions. Glass raw materials were used as raw materials for the synthesis of substrates. In order to create open porosity, a carbonate blowing agent (chalk) was introduced into the initial mixture. Foaming additive served as sodium nitrate, a source of copper ions - copper sulfate (copper sulfate). A distinctive feature of the synthesis method was the combination of wetting the initial mixture and its rapid heating to maximum temperature. This mode was used to increase the porosity of the resulting structure. It was found that the water absorption of the obtained substrates increases with an increase in the concentration of copper ions in them. The resulting materials, due to the increased content of copper ions in them, may have a fungicidal effect. Perhaps their use in crop production, landscape design, the construction industry in conditions of high humidity.
\end{abstract}

\section{Introduction}

Foam glass having a porous structure is made from finely ground glass breakage mixed with additives of pore-forming substances (blowing agents). The mixture is heated at a temperature of $800-900^{\circ} \mathrm{C}$. The glass particles are fused, and the gases emitted by the blowing agents swell the molten glass, forming a large number of pores in it. When the mass is cooled, a strong cellular material is obtained [1,2]. Foam glass has several advantages. Compared to other materials: relatively high mechanical strength, incombustibility, water resistance, biological resistance. This promising material is used as insulation, sound insulator, moisture insulator, decorative material [2-5], aggregate of lightweight concrete. In construction, foam glass is used to insulate walls and ceilings of buildings, it is also used for thermal insulation of hot surfaces and thermal units: stoves, dryers, etc. Moisture-proof foam glass is used for thermal insulation of objects operating at variable temperatures or high humidity. Decorative painted or glazed foam glass is used for interior and exterior cladding of buildings and premises, including in the form of panels, while decorative and thermal insulation are combined.

Granular foam glass is a promising material for heat-insulating fillings, for thermal insulation of surfaces of complex configuration, for the manufacture of lightweight

\footnotetext{
*Corresponding author: adres11111111@yandex.ru
} 
concrete and lightweight structures. It has been shown that the use of foam glass in the form of bulk thermal insulation of foundations can significantly reduce the construction budget [6].

Based on foam glass, substrates for crop production have been developed. In particular, the GrowPlant substrate, which is a granular foam glass, is proposed to be used for hydroponic systems, soil improvement, landscape design, filling landscape gabions, and creating green roofs [7].

Foam glass is mainly obtained by the powder method [8]. The powder method consists in sintering a mixture of glass powder and the addition of blowing agents, which contribute to the formation of a gas phase during heating of the mixture and subsequent annealing. Annealing of the resulting foam glass is carried out in order to relieve the internal stresses of the material. In the process of heating the charge, when the temperature exceeds the softening temperature of the glass, sintering of the glass particles begins, while the particles of the blowing agent are blocked by softened glass. When a certain temperature is reached, they begin to emit gases, which cause foaming of the glass melt. In the sintered material, pores appear where gas-forming particles are blocked during gas evolution. The nature of the porosity of the resulting foam glass, its physicomechanical properties, and the field of application largely depend on the type of blowing agent used and the concentration. Blowing agents are divided into neutralization and redox.

The first type includes metal carbonates. Apply marble chips, chalk, limestone. When heated, carbonates enter into thermal reactions, releasing carbon dioxide $\mathrm{CO}_{2}$ by the reactions:

$$
\begin{gathered}
\mathrm{CaCO}_{3}+\mathrm{SiO}_{2} \rightarrow \mathrm{CaSiO}_{3}+\mathrm{CO}_{2} \uparrow \text { (substitution reaction) } \\
\mathrm{CaCO}_{3} \rightarrow \mathrm{CaO}+\mathrm{CO}_{2} \uparrow \text { (decomposition reaction). }
\end{gathered}
$$

The intense evolution of carbon dioxide destroys the walls of the pores in the glass, which results in a labyrinthine system of communicating pores. The resulting foam glass is characterized by high water absorption and soundproofing properties.

The second type of blowing agents include substances containing carbon: graphite, chark, soot, anthracite. Carbon-containing substances, when the mixture is heated, are oxidized by gases dissolved in the glass melt, as a result, gaseous products are formed, foaming the glass melt. When using such blowing agents, closed-cell foam glass is formed. If anthracite serves as a blowing agent, partially closed pores are formed. Closed cell foam glass is characterized by high thermal insulation properties.

In the synthesis of foam glass, it is important to ensure the conditions under which, during a periodic intense gas reaction, the viscosity of the glass melt will be high enough to resist tearing of the film glass. This condition is a component of the initial data.

In the process of heating, the initial mixture undergoes a number of physicochemical changes: softening of glass particles during heating, sintering of particles with shrinkage of the mixture, decrease in viscosity of the glass mass, thermal reactions involving blowing agents with the appearance of a gas phase, formation of pores in the glass mass, growth in their size, increase in the volume of glass mass stabilization of the resulting pore structure, the acquisition of the obtained material hardness and strength as a result of its successive transition in the process of cooling from plastic-viscous state in vitreous, then solid.

The development of foam glass production largely depends on the available raw material base. Therefore, one of the key trends in this area is to find opportunities to use a variety of industrial and consumer waste feedstock. To obtain foam glass, unsorted cullet from household waste is used [9]. A similar raw material served to obtain material with high insulating properties for use in wall constructions as self-supporting insulating bases $[10,11]$. 
A method has been developed for producing block foam glass based on cullet using dolomite flour as a blowing agent, and liquid glass as a structure modifier [12]. The methods for producing foam glass from various wastes were investigated: cathode ray tube glasses and television panels, monitors and other electronic devices [13-15], fluorescent lamp glasses [16], blast furnace wastes [17], and TPP slag waste; from minerals - for example, from diatomite. Glass ceramic foams were obtained using waste glass and ash as the main components, borax as flux and calcium carbonate as a blowing agent. An optimal synthesis mode was proposed: temperature $-800^{\circ} \mathrm{C}$, time $-45 \mathrm{~min}$.

To reduce the cost of foams, attempts are made to optimize the process of their production (reduction of energy consumption, reduction of the preparation time of the charge, etc.) and improve operational properties. It is shown that preliminary briquetting of the foam glass mixture using water as a technological bond helps to improve the conditions for expanded glass and increase its physical and technical parameters.

Obtained heat-insulating foam glass with protective and decorative coating that enhances the durability and water resistance of the material improves decorative properties. It is used in the architectural and architectural design of buildings.

Facing materials with an adjustable pore structure are made of foam glass. Thermal stability of block foamed glass is increased due to reduction of annealing time, achieving reduction in power consumption. Synthesized foam glass, protecting against the microwave action due to the introduction of additives to the initial charge of ilmenite (titaniferous hematite).

When using foam glass in conditions of high humidity during long-term operation of the structure in a subtropical climate, special attention is paid to biological resistance to the action of mold fungi. It was found that this material is generally stable, however, the products of the vital activity of fungi lead to an increase in the sorption moisture of foam glass.

Methods have been developed for the production of colored foam glass materials for decorative purposes. To color the foam glass, small additives of metal ions are introduced into its composition at the synthesis stage. For example, a blowing agent (chalk) is impregnated with dilute solutions of salts of cobalt, nickel, copper manganese, dried, mixed with ground glass, and foam glass is synthesized.

Foam glass with the addition of copper ions is of particular interest. Copper compounds are known to have a fungicidal effect. Copper-based preparations are widely used in crop production to combat plant fungal diseases. Perhaps the addition of copper salts can have a positive effect on the biostability of foam glass and even endow it with fungicidal properties. The question is how to select the necessary concentration of copper ions for this. It is advisable to synthesize samples with increased concentrations of copper ions and to study their effect on the properties of the substrate.

\section{Materials and methods}

In solving this problem, a glass break was used, as in [9-11], a blowing agent, a blowing agent, and a salt of divalent copper. The glass break was washed, dried and crushed. The resulting material was subjected to fine grinding to obtain the maximum possible specific surface area, which has a significant effect on the course of physicochemical firing processes and the properties of the substrate. Grinding was carried out to a fineness characterized by a residue of not more than $5 \%$ on a sieve with a mesh size of $0.063 \mathrm{~mm}$. This type of grinding provided melt formation at temperatures in the range $700-800{ }^{\circ} \mathrm{C}$. The blowing agent was calcium carbonate (chalk) in an amount of $2 \%$ of the mass. by weight of glass. The fineness of grinding chalk is similar to grinding glass. To the resulting mixture was added approximately $35 \%$ of the mass. water for better homogenization [12], 
mixed and re-ground. The mixture was dried at a temperature of $100^{\circ} \mathrm{C}$ for 10 minutes, after which the same amount of water was re-added, mixed and ground. Adding water to the composition of the charge increases the porosity of the resulting foam glass due to the formation of water vapor during the synthesis process, as well as accelerating the decomposition of foaming agents. The latter contributes to the creation of a stable cellular structure with improved operational properties. To achieve the highest foaming intensity and decrease in density, as in, a foaming additive was introduced - sodium nitrate NaNO3 in the recommended amount of 3\% of the mass. The thermal decomposition of sodium nitrate with the release of gaseous oxygen occurred at $400^{\circ} \mathrm{C}$, before the carbonate blowing agent $\left(600-900^{\circ} \mathrm{C}\right)$ entered into the reaction. In order for foaming to proceed actively, it is necessary to partially combine in time the decomposition of sodium nitrate and calcium carbonate. For this purpose, rapid heating of the mixture from room temperature to maximum $\left(900^{\circ} \mathrm{C}\right)$ was used. The salt of divalent copper was copper (II) sulfate $\mathrm{CuSO}_{4} \cdot 5 \mathrm{H}_{2} \mathrm{O}$ in amounts of $3,5,10 \%$ of the mass. by weight of glass in terms of copper ions $\mathrm{Cu}$ (II). The composition of the mixture of samples of foam glass substrate is shown in Fig. 1.

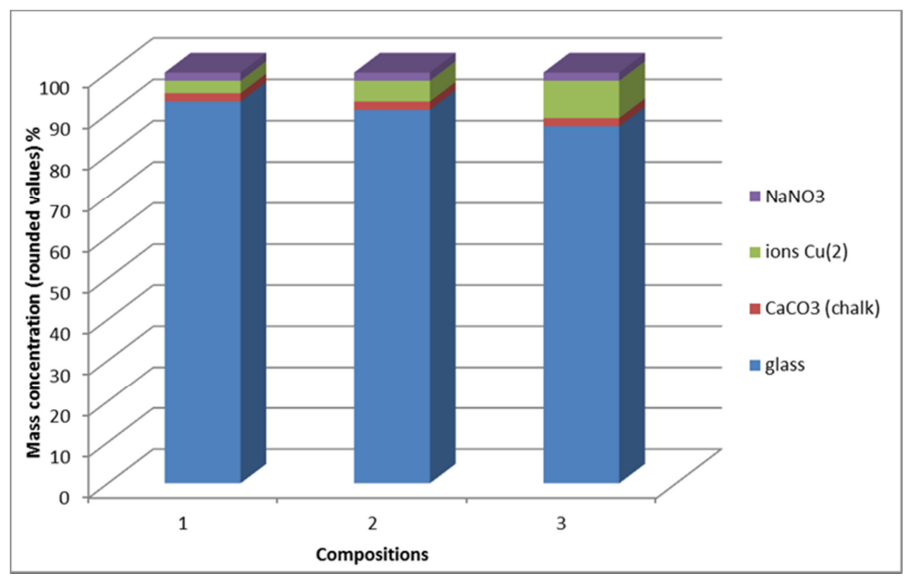

Fig. 1. The composition of the mixture to obtain a substrate based on foam glass.

Samples were kept at the maximum temperature for one hour. Thereafter, heating was stopped, and further slow cooling took place for five hours to stabilize the structure of the resulting substrate. The main physico-chemical processes:

1. The softening of the glass particles in the temperature range $700-750^{\circ} \mathrm{C}$, sintering them together, the formation of thin films of glass between the individual particles.

2. Decomposition of a blowing agent (sodium nitrate) and oxygen evolution at a temperature of about $400^{\circ} \mathrm{C}$ according to the reaction:

$$
2 \mathrm{NaNO}_{3} \rightarrow 2 \mathrm{NaNO}_{2}+\mathrm{O}_{2} \uparrow
$$

3. The formation of carbon dioxide from a carbonate blowing agent (chalk) due to reactions of:

3.1 Interaction of calcium carbonate with silicon dioxide contained in the structure of glass:

$$
\mathrm{CaCO}_{3}+\mathrm{SiO}_{2} \rightarrow \mathrm{CaSiO}_{3}+\mathrm{CO}_{2} \uparrow \text { (at temperatures above } 600^{\circ} \mathrm{C} \text { ), }
$$

3.2 decomposition of calcium carbonate:

$$
\mathrm{CaCO}_{3} \rightarrow \mathrm{CaO}+\mathrm{CO}_{2} \uparrow \text { (at temperatures above } 800{ }^{\circ} \mathrm{C} \text { ). }
$$

4. Copper sulfate pyrolysis (II) at temperatures $650-700{ }^{\circ} \mathrm{C}$ ):

$$
2 \mathrm{CuSO}_{4} \rightarrow 2 \mathrm{CuO}+2 \mathrm{SO}_{2} \uparrow+\mathrm{O}_{2} \uparrow
$$

followed by thermal interaction between the formed copper oxide $\mathrm{CuO}$ and glass components. As a result of this interaction, copper ions $\mathrm{Cu}$ (II) are introduced into the 
structure of the resulting foam glass due to the formation of complex silicates of various compositions. The resulting foamglass acquired a blue color, characteristic of colored glasses with the addition of copper ions.

5. Expansion of viscous glass melt by the evolved gases, inflation of continuous glass melt films by the evolving gases and the formation of pores in the material.

6. Fastening resultant cellular structure; material hardness and strength acquisition.

\section{Discussion}

As a result of synthesis of the substrate samples were obtained on the basis of foam glass with additives of copper ions Fig.2.

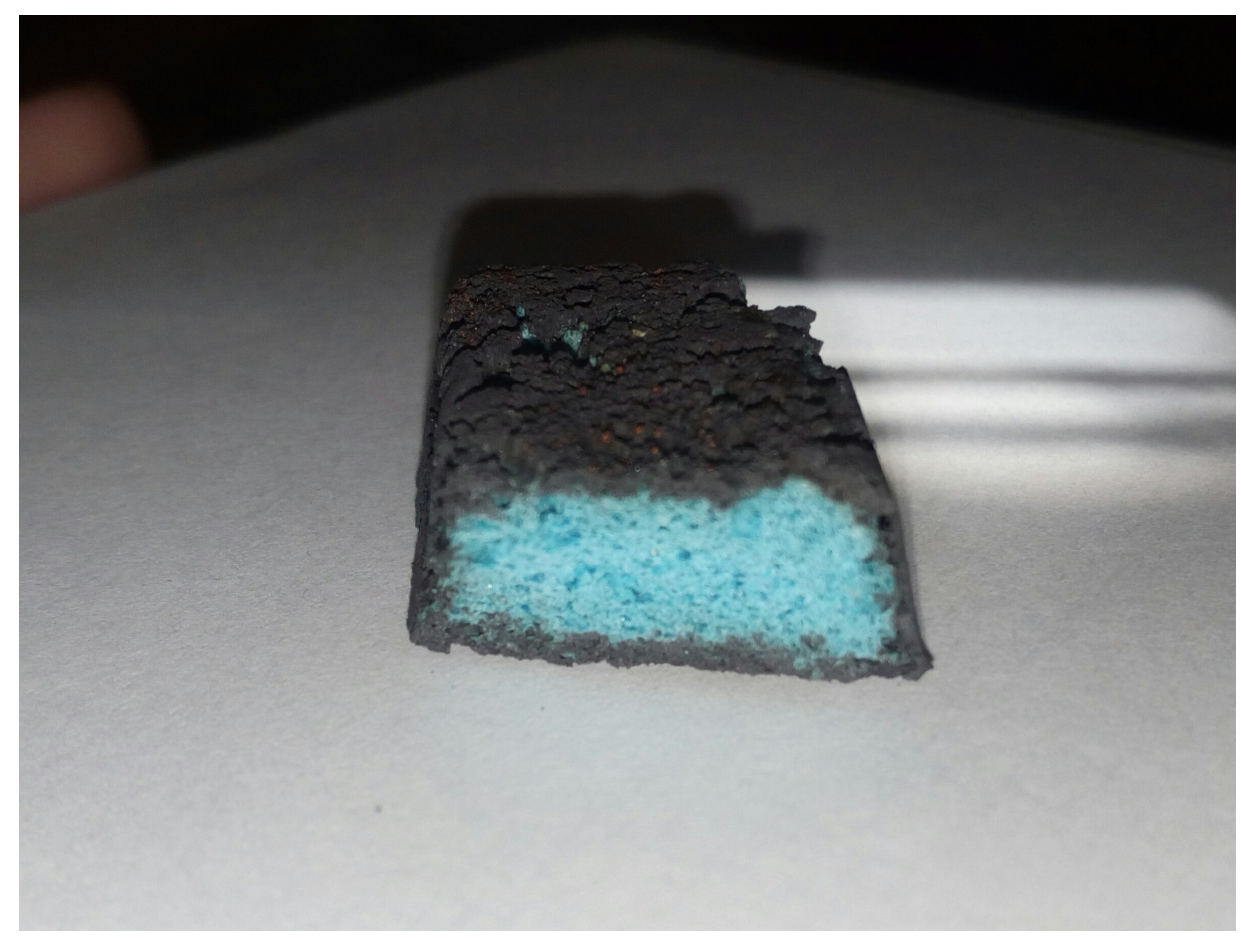

Fig.2 The sample of foam glass with additives of copper ions

As can be seen from table 1, the water absorption of the substrates increases with increasing concentration of copper ions. The greatest water absorption is observed when the content of copper ions in a concentration of $10 \%$ of the mass. Due to its fungicidal properties, such a substrate is suitable for use in crop production. And the decorative properties of this material will allow its use in landscape design and green roofs. Substrates with a lower concentration of copper ions will serve as an additive in concrete or plaster.

The fungicidal effect of the substrates helps to reduce environmental pollution, as it contains copper ions in bound form. Indeed, in the traditional processing of plants, some of the preparations containing copper inevitably fall into the soil, storm and ground water in dangerous quantities. In a humid subtropical climate, we assume the gradual release of copper ions from the substrate with a prolonged effect. It will be possible to reduce the number of chemical treatments of plants with fungicides. 
Table 1. Water absorption of substrates at different concentrations of copper ions $\mathrm{Cu}$ (II)

\begin{tabular}{|c|c|}
\hline $\begin{array}{c}\text { Copper ion concentration } \\
\mathrm{Cu}(\mathrm{II}) \text { \% mass. }\end{array}$ & $\begin{array}{c}\text { Water absorption, } \\
\% \text { mass. }\end{array}$ \\
\hline 3 & 12,6 \\
\hline 5 & 14,6 \\
\hline 10 & 17,1 \\
\hline
\end{tabular}

\section{Results}

1. Porous, colored substrates containing 3 to $10 \%$ of the mass of copper ions $\mathrm{Cu}$ (II) were synthesized from glass wastes. A feature was the addition of water to the initial mixture in combination with rapid heating to a maximum temperature. This mode was used to increase the porosity of the resulting structure.

2. An increase in the water absorption of the substrates is observed with an increase in the concentration of copper ions.

3. A substrate with a copper ion content of $10 \%$ of the mass is suitable for crop production and landscape design.

4. A substrate with a copper ion content of less than $10 \%$ of the mass is applicable in a subtropical climate as an additive to the heat-insulating materials of plasters and lightweight concrete.

\section{References}

1. N.I. Minko, Heat-insulating glass materials (2016)

2. N.I., Minko, O.V., Puchka, E.I. Evtushenko, Bas. Res. 6-4, 849-854 (2013)

5. I. S. Grushko Gla. Cera. 10, 3-9 (2016)

4. A. A. Ketov, A. V. Tolmachev, Build. Mater., 1, 17-31 (2015)

5. A. A. Ketov, Build. Mater., 3, 79-81 (2016)

6. L.V. Sapacheva, S. Yu. Goreglyad, Build. Mater., 1, 30-31 ( 2015)

7. Grow Plant, http://www.grow-plant.com

8. V. E. Kogan, Gla. Cera., 12, 3-7 (2013)

9. N. E. Stakhovskaya, A. I. Chervony, Build. Mater., 11, 24-26 (2012).

10. Ya. I. Vaysman, P. A. Ketov, A. D. Potapov, Vestnik MGSU, 7, 85-92. (2014)

11. Ia. Vaisman, A. Ketov, Iu. Ketov, Ceram. Intern., 42, 15261-15268, (2016)

12. G. Ya. Musafirova, E. V. Musafirov, M. V. Lyshchik, Tech. Technol. Silic., 1, 7-11 (2017)

13. H. W. Guo, Y. X. Gong, S. Y. Gao, Mater. Lett.64, 997-999(2010)

14. Lee Chul-Tae, J. Ind. Eng. Chem., 19, 1916-1925 (2013)

15. Q. Zhang, Constr. Build. Mater. 111, 105-110 (2016)

16. C. Mugoni, Ceram. Intern., 41, 3400-3408, (2015)

17. L. Ding, Mater. Lett. 141, 327-329 (2015) 